\section{Measurement of transverse and sagittal diameter of the lumbar vertebral canal in people from Western region of Nepal}

\section{Shrestha $B,{ }^{1^{*}}$ Dhungana $S^{2}$}

${ }^{1}$ Orthopedic Department, Gandaki Medical College, ${ }^{2}$ Radiology Department, Gandaki Medical College

*Correspondence to: Dr Bhola Shrestha, Orthopedic Department, Gandaki Medical College, Pokhara, Nepal. email: bhola4355@hotmail.com, Tel.no.: (+977)9856028656

\begin{abstract}
INTRODUCTION: Size of the canal diameter is one among several factors responsible for lumbar canal stenosis. The study aims to measure the transverse and sagittal diameter of the lumbar vertebral canal in people from Western region of Nepal and compare with the published results.
\end{abstract}

MATERIALS AND METHODS: Fifty young patients (24 males and 26 females) complaining of LBP were done X-ray of lumbar spine in AnteroPosterior (AP)/ Lateral in supine views. From the images, midsagittal (AP) dimensions, transverse (interpedicular) distances and width of vertebral body were measured at each level with the help of electronic calipers.

RESULTS: The mean transverse diameter of lumbar canal ranged from $24.8 \mathrm{~mm}$ at $\mathrm{L} 1$ to 33.25 $\mathrm{mm}$ at L5. This gradual increase in the transverse diameter from L1 to L5 was statistically significant. Measurement of lumbar vertebral width ranged from $41.37 \mathrm{~mm}$ at $\mathrm{L} 1$ and $52.96 \mathrm{~mm}$ at L5. There was gradual increase in the size from L1 to L5. But the measurement of AP distance showed a gradual decrease in diameter from $\mathrm{L}_{1}$ to $L_{5}$. The decrease in the AP diameter from $L_{1}$ to $L 2$ and Canal body ratio was not constant at all levels.

CONCLUSIONS: Our hospital based data showed that the patients from western region of Nepal have smaller canal size. Therefore, the patients from western region of Nepal may be more prone to develop spinal canal stenosis.

KEY WORDS: Interpedicular distance, Lumbar vertebrae, Spinal canal, Width of vertebral body

Article submitted 10 January. Reviewed 12 February. Author correction 15 February. Final version accepted 28 February 2012 


\section{INTRODUCTION}

Low backache is a common clinical problem. The etiology in many of these patients is narrowing of the lumbar canal. The incidence and implication of lumbar canal stenosis are gaining attention. The values of normal transverse (interpedicular) and sagittal (midsagittal) diameters are different at various levels of lumbar spinal canal in individuals of the same race and differ at identical levels in individuals of various races. Alterations in the linear dimensions may be deduced from careful inspection of plain radiographs. A number of authors have discussed methods of measuring the spinal canal. ${ }^{1,2}$ Spinal canal stenosis is a medical condition in which the spinal canal narrows and compresses the spinal cord and nerves. ${ }^{3}$ This is usually due to the common occurrence of spinal degeneration that occurs with aging. It can also sometimes be caused by spinal disc herniation, osteoporosis or a tumor. In the cervical (neck) and lumbar (low back) region stenosis can be a congenital condition to varying degrees.

Spinal canal stenosis may affect the cervical, thoracic or lumbar spine. In some cases, it may be present in all three places in the same patient. Among them, lumbar canal stenosis is the most common. Lumbar spinal stenosis results in low back pain as well as pain or abnormal sensations in the legs, thighs, feet or buttocks, or loss of bladder and bowel control.

There are varieties of investigations to confirm spinal canal stenosis. More specialized tests include Magnetic Resonance Imaging (MRI). These are ideal for diagnosing a deformed disc and affected spinal nerve. In the absence of signs or symptoms suggesting severe nerve damage, MRI are very rarely indicated or ordered in early course of the evaluation. We usually order X-ray to evaluate back pain for causes other than a prolapsed disc. Because of cost, availability of the test, and the fact that the findings rarely affect initial treatment decisions, $\mathrm{X}$ rays are preferred in our set up. The transverse and sagittal diameter of the lumbar vertebral canal in people from Western region of Nepal is presented and compare with the published results.

\section{MATERIALS AND METHODS}

Fifty young patients(24 males and 26 females) complaining of LBP were enrolled in this study. The study was done in Fishtail hospital and Gandaki Medical college, Pokhara, Nepal for six months (July to Dec 2012). In the present study, an attempt has been made to establish the range of transverse, antero- posterior diameter and canal/ body ratio of lumbar spinal canal in young people from western region of Nepal. These patients were sent to do Xray of Lumbar spine in AP/ Lateral in supine views. $\mathrm{X}$-rays were prefered than MRI Scan because of easy availabilty and the cost factor. The age of the patients ranged from 20-50 yrs.The patients of less than 20 years and more than 50 years were excluded. All images were taken with $300 \mathrm{~mA}$ Xray machine with the specimen at a distance of $100 \mathrm{~cm}$ from the tube to make them equality. The images were magnified and midsagittal (AP) dimensions, transverse (interpedicular) distances, and width of vertebral body were measured at each level with the help of electronic calipers.

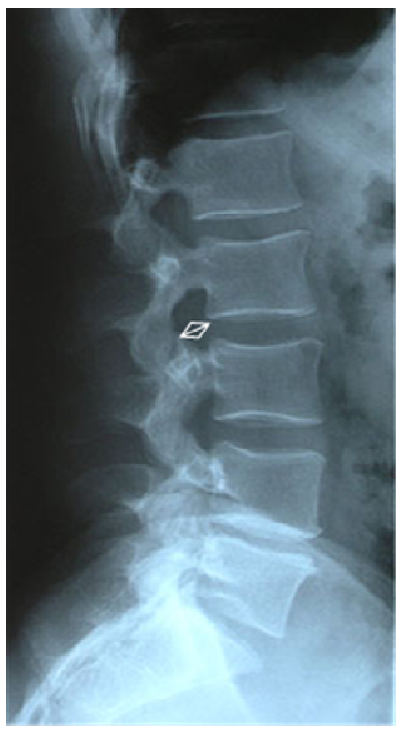

Figure 1: midsagittal diameter of L2

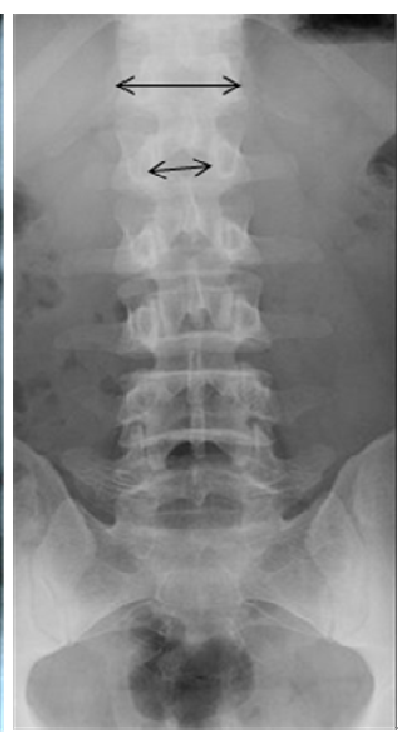

Figure 2: width of vertebral body L1 (above) and transverse diameter of L2 (below)
The midsagittal canal diameter was taken as the shortest midline perpendicular distance from posterior margin of vertebral body to inner margin of neural arch . Transverse diameter of the lumbar spinal canal was measured as the minimum distance between the medial surfaces of the pedicles of a given vertebra (Inter-pedicular distance) (Jones \& Thomson, 1968) in AP view of X ray. ${ }^{4}$ Transverse diameter of the vertebral body was measured as the minimum distance across the waist of the vertebral body, which is between its upper and lower border. In order to reduce error due to human element, measurement at each level was made twice and average was obtained. From these measurements, mean and standard deviation were calculated for all levels. All the data were analyzed by SPSS 17.0. Two groups' samples were compared by paired $\mathrm{T}$ test. 
The results were considered to be significant with p-value of $<0.05$.

\section{RESULTS}

The transverse diameter of the lumbar canal ranged from $19.8 \mathrm{~mm}$ to $30.9 \mathrm{~mm}$ at L1, $20.8 \mathrm{~mm}$ to 30.5 $\mathrm{mm}$ at $\mathrm{L} 2,21.3 \mathrm{~mm}$ to $34.2 \mathrm{~mm}$ at $\mathrm{L} 3,22.6 \mathrm{~mm}$ to $33.7 \mathrm{~mm}$ at $\mathrm{L} 4$ and $26 \mathrm{~mm}$ to $39.6 \mathrm{~mm}$ at L5. There was a gradual increase in the transverse diameter from $L_{1}$ to $L_{5}$. The transverse diameter of the lumber canal was statistically significant between L1 and L2 level ( $p$ value $<0.01$ ), L2 and L3 level ( $p$ value $<0.01$ ), L3 and L4 level ( $p$ value $<0.002$ ) and L4 and L5 level ( $p$ value $<0.001$ ). Measurement of lumbar vertebral width ranged from $41.37 \mathrm{~mm}$ at L1 and $52.9 \mathrm{~mm}$ at L5. There was also gradual increase in the size from L1 to L5. The width of different lumbar vertebra was statistically significant between L1 and L2 ( $p$ value $<0.001$ ), L2 and L3 ( $p$ value $<0.001$ ), L3 and L4 ( $\mathrm{p}$ value< 0.001), L4 and L5 (p value $<0.001$ ). (Table1).

Table 1. Mean diameter in L1 to L5 expressed in millimeter

\begin{tabular}{lccc}
\hline $\begin{array}{l}\text { Lumbar } \\
\text { vertebra } \\
\text { l level }\end{array}$ & $\begin{array}{c}\text { Transverse } \\
\text { Diameter } \pm \\
\text { SD }\end{array}$ & $\begin{array}{c}\text { Lumbar } \\
\text { width } \pm \text { SD }\end{array}$ & $\begin{array}{c}\text { Sagittal } \\
\text { (AP) } \\
\text { Diameter } \pm \\
\text { SD }\end{array}$ \\
L1 & $24.86 \pm 2.5$ & $41.37 \pm 2.9$ & $12.84 \pm 0.9$ \\
L2 & $25.71 \pm 2.6$ & $43.36 \pm 3.1$ & $12.44 \pm 1.0$ \\
L3 & $26.6 \pm 2.6$ & $45.92 \pm 3.2$ & $11.59 \pm 1.2$ \\
L4 & $27.68 \pm 3.1$ & $47.93 \pm 3.8$ & $10.27 \pm 1.7$ \\
L5 & $33.25 \pm 3.1$ & $52.96 \pm 4.2$ & $9.81 \pm 1.9$ \\
\hline
\end{tabular}

But the measurement of AP distance of the lumbar spinal canal in the X-rays showed a gradual decrease in diameter from $\mathrm{L}_{1}$ to $\mathrm{L}_{5}$. The distance varied from $12.84 \mathrm{~mm}$ at $\mathrm{L}_{1}$ to $9.81 \mathrm{~mm}$ at $\mathrm{L}_{5}$. The decrease in the antero-posterior diameter from $\mathrm{L}_{1}$ to L2 was not statistically significant ( $p$-value, $>0.05$ ). However, when we compared L2 with L3, L3 with L4 and L4 with L5, statistically significant results were obtained ( $p$ value $<0.05$ ).

As shown in table 2 , the canal body ratio gradually decreased from L1 to L4 and increased at L5 level. However, the canal body ratio was not constant in all levels. This was not statistically significant. (Table 2).

The transverse diameter of peoples of western region of Nepal was also compared with the male and female adults of Saudi based on the published
Table 2. Canal body ratio of L1 to L5 vertebra

\begin{tabular}{llll}
\hline $\begin{array}{l}\text { Lumbar } \\
\text { vertebral } \\
\text { level }\end{array}$ & $\begin{array}{l}\text { Transverse } \\
\text { Diameter }\end{array}$ & $\begin{array}{l}\text { Lumbar } \\
\text { width }\end{array}$ & $\begin{array}{l}\text { C/B } \\
\text { ratio }\end{array}$ \\
\hline L1 & 24.86 & 41.37 & 0.6 \\
L2 & 25.71 & 43.36 & 0.59 \\
L3 & 26.6 & 45.92 & 0.57 \\
L4 & 27.68 & 47.93 & 0.57 \\
L5 & 33.25 & 52.96 & 0.62 \\
\hline
\end{tabular}

literature (Table 3). There is considerable variation in the transverse diameter of the spinal canal between the people of western region of Nepal and adult patients of Saudi Arab.

Table 3. Comparing transverse diameter of lumbar canal in our study with Kuofi et al.

\begin{tabular}{|c|c|c|c|}
\hline $\begin{array}{l}\text { Lumbar } \\
\text { vertebral } \\
\text { level }\end{array}$ & $\begin{array}{ll}\text { Our } & \text { study } \\
(\mathrm{mm}) & \end{array}$ & $\begin{array}{l}\text { Male of } \\
\text { adult saudi } \\
(\mathrm{mm})\end{array}$ & $\begin{array}{l}\text { Female } \\
\text { of adult } \\
\text { saudi } \\
(\mathrm{mm})\end{array}$ \\
\hline L1 & 24.8 & 26 & 24.1 \\
\hline $\mathrm{L} 2$ & 25.7 & 27.7 & 25.7 \\
\hline L3 & 26.6 & 29.7 & 27.3 \\
\hline L4 & 27.6 & 32.5 & 30.1 \\
\hline L5 & 33.2 & 37.4 & 34.4 \\
\hline \multicolumn{4}{|l|}{ Kuofi et al ${ }^{10}$} \\
\hline
\end{tabular}

In this present study, we determine standard normal minimum transverse and midsagittal diameter of lumbar canal as a preliminary reading to elicit the spinal canal stenosis. It has been found that the reduction of coronal diameter of the lumbar spinal canal, caused by reduction in the inter-pedicular distance, is second most common cause of narrowing of the lumbar spinal canal after the reduction in the sagittal diameter, caused by short pedicles. So, we undertook the steps to determine the standard inter-pedicular distance to detect spinal canal stenosis. Earlier study of canal/body ratio in plain antero-posterior radiographs shows that C/B ratio remain constant $(0.6)$. Hinck et al. (1966) have shown that before the age of 19 years, the lumbar spinal canal is distinctly narrower than it is in the adult. ${ }^{5}$ Inclusion of such young subjects in the sample could result in lowering of the value of mean IPD and mean width. So we included the patients of age groups more than 20 years and below 50 years age.

The importance of the rediographic by Elsberg 
and Dyke 6 who established the normal ranges of interpediculate distance in the thoracic and lumbar spine and applied this to the diagnosis of intraspinal tumors. These early works concerning the large spinal canal stimulated interest in the small canal. Though sparpyener is credited with the first recognizing the clinical importance of lumbar canal stenosis.7 Verbiest was first to assess stenosis quantitatively. ${ }^{8}$ He classified stenosis as relative, when the sagittal diameter is $12 \mathrm{~mm}$ and absolute when the diameter is $10 \mathrm{~mm}$ or less. ${ }^{9}$

However, the value of the lowest normal interpedicular and midsagittal diameters is different in the various levels of the lumbar vertebral canal of individuals of the same race and the differ at identical levels in individuals of various races. On comparison of the transverse diameter of spinal canal in our subjects with Saudi people based on the published literature, there was considerable variation between the people of western region of Nepal and adult patients of Saudi Arab. ${ }^{10}$

Poostacchini petal in a morphometric study of 121 skeletons(63 Italians and 58 Indians) found that the mean AP diameter to be significantly greater in Italion skeletons. Hinck et al ${ }^{11}$ measured the AP diameter of spinal canal on plain radiographs in western population. The mean AP diameter in his study of 49 adults was $21.8 \mathrm{~mm}$ at $\mathrm{L} 1,21.7 \mathrm{~mm}$ at $\mathrm{L} 2,21.5 \mathrm{~mm}$ at $\mathrm{L} 3,21.6 \mathrm{~mm}$ at $\mathrm{L} 4$ and $21.4 \mathrm{~mm}$ at L5, different than the corresponding levels in our study.

\section{CONCLUSION}

Of the several factors responsible for lumbar canal stenosis, one of the factor is size of the canal diameter. Our hospital based data showed that the patients from western region of Nepal have smaller canal size. Therefore, these patients may be more prone to develop spinal canal stenosis. A large community based study is needed to further confirm this hospital based findings.

\section{REFERENCES}

1. Janjua MZ, Muhammad F. Measurement of normal adult lumbar spinal canal. J Pak Med Assoc 1989;39:264268.

2. Gupta SK, Roy RC, Srivastava A. Sagittal diameter of cervical canal in normal Indian adults. Clin Radiol 1982;33:681-685.

3. Hsaing JK. Spinal stenosis. eMedicine. Available from: http://emedicine. medscape. com/article/ 1913265overview. Accessed January 2013.

4. Jones RAC, Thomson JLG. The narrow lumbar canal. A clinical and radiological review. J Bone \& Joint Surg Br 1968;50:588-594.

5. Hinck VC, Clark WM, Hopkins CE. Normal interpedicular distances (minimum and maximum) in children and adults. Roentg 1966;97:141-153.

6. Elsberg CA, Dyke CG. Diagnosis and localization of tumors of spinal cord by means of measurement made on $X$ ray flims fo the vertebra. Bul Neur Inst NY 1934;3:359.

7. Sarpyener MA. Congenital stricture of spinal canal. J Bone Joint Surg Am 1945;27:70-79.

8. Verbiest H. Futher experiences on the pathological influence of developmental narrowness of bony lumbar vertabral canal. J Bone Joint Surg 1955;37:576-583.

9. Verbiest H. Neurogenic intermittent claudication with special reference to stenosis of lumbar vertebral canal. Amsterdam; North Holland; 1976.

10. Amonoo-Kuofi HS, Patel PJ, Fatani JA. Transverse diameter of the lumbar spinal canal in normal adult Saudis. Acta Anat 1990;137:124-128.

11. Hinck VC, Hoopkins CE, Clark WM. Sagittal diameter of the lumbar spinal canal in children and adults Radiol. Radiol 1965;85:929-937.

\section{Citing this article}

Shrestha B, Dhungana S. Measurement of transverse and sagittal diameter of the lumbar vertebral canal in people from Western region of Nepal. Int J Infect Microbiol 2013;2(2):55-58. 